\title{
Patterns of intraspecific morphological variability in soil mites reflect their dispersal ability
}

\author{
Julia Baumann ${ }^{1}$ (iD \\ Received: 22 September 2020 / Accepted: 18 December 2020 / Published online: 25 January 2021 \\ (c) The Author(s) 2021
}

\begin{abstract}
The ability to disperse is one of the most important factors influencing the biogeography of species and speciation processes. Highly mobile species have been shown to lack geographic population structures, whereas less mobile species show genetically strongly subdivided populations which are expected to also display at least subtle phenotypic differences. Geometric morphometric methods (GMM) were now used to analyze morphological differences between European populations of a presumed non-phoretic, little mobile mite species in comparison to a highly mobile, phoretic species. The non-phoretic species Scutacarus carinthiacus showed a phenotypic population structure, whereas the phoretic species $S$. acarorum displayed homogeneity. These different patterns most probably can be explained by different levels of gene flow due to different dispersal abilities of the two species. GMM proved to be a sensitive tool that is especially recommendable for the analysis of (old) museum material and/or specimens in microscopic slides, which are not suitable for molecular genetic analysis.
\end{abstract}

Keywords Scutacaridae $\cdot$ Heterostigmatina $\cdot$ Geometric morphometrics $\cdot$ Phoresy

\section{Introduction}

Dispersal is one of the most important characteristics of all living beings. It can be achieved through active movement or through passive transportation, and dispersal modes are among the most important factors influencing a species' biogeography (Lomolino et al. 2010) and speciation processes. The phylogeographic patterns of various taxa have been shown to differ clearly between highly mobile species versus species with limited dispersal abilities (e.g., sponge-dwelling shrimps with vs. without swimming larvae, Duffy 1993; winged vs. flightless tenebrionid beetles, Papadopoulou et al. 2009; or various benthic

\footnotetext{
Supplementary Information The online version contains supplementary material available at https:// doi.org/10.1007/s10493-020-00587-y.
}

Julia Baumann

julia.baumann@uni-graz.at

1 Institute of Biology, Department of Biodiversity and Evolution, University of Graz,

Universitätsplatz 2, $8010 \mathrm{Graz}$, Austria 
marine invertebrates with high vs. low dispersal potential, Haye et al. 2014). In general, highly mobile species lack geographic population structure, whereas species with limited dispersal show genetically strongly subdivided populations. Morphological characters evolve more slowly than neutral genetic data and thus provide less resolution in analyses of patterns of population differentiation (Miller-Butterworth et al. 2003), but given sufficient time, geographic isolation between populations should also be reflected in subtle morphological differences caused by random Brownian motion (as explained in the glossary of Fišer et al. 2018: "Brownian motion. A model of trait evolution, sometimes called random walk, which assumes neutral and gradual evolution of traits due to genetic drift. Change in mean phenotype is expected to be nondirectional and occurs at a constant rate, whereas variance among species is linearly related to the amount of time since divergence."). As such subtle morphological differences are not visible by the human eye, the application of adequate morphometric methods to detect them is indispensable.

Mites (Acari) are tiny arachnid organisms that have conquered practically all ecosystems of our planet: they can be found from the deepest depths of the ocean up to mountain heights, they occur in different substrates, and they can even be important pest species affecting plants and animals. Like many other flightless microarthropod taxa, hundreds of mite taxa have huge geographical ranges, which indicates that efficient dispersal pathways must exist- the mode of dispersal, however, is often poorly understood (Schuppenhauer et al. 2019). Given the mites' minute size, long-distance dispersal by active locomotion can only play a minor role. Anyhow, it seems to be important on a smaller scale, like the immediate colonialization of new habitats (Auger et al. 1999; Lehmitz et al. 2012). Phoresy, the act of using larger and more mobile animals as transport hosts, surely is one of the most effective modes of dispersal for mites as it allows for covering great distances and for targeted reaching of suitable habitats because of host specificity (Binns 1982; Krantz and Walter 2009; Baumann 2018). Usually, mites mount their hosts actively and have morphological adaptations for attachment on the host (like enlarged claws or sucker plates), but phoresy can also happen passively when hosts displace the mites unintentionally, for example when they are transported adhering to birds' feathers (Lebedeva and Krivolutsky 2003). Other possible mechanisms are dispersal via air currents (anemochory), which has been demonstrated for soil-living oribatids (Lehmitz et al. 2011) and various plant-inhabiting mites (Boykin and Campbell 1984; Jung and Croft 2001; Michalska et al. 2010), or drift on running fresh water (Schuppenhauer et al. 2019) or ocean currents (Pfingstl 2013, 2017; Lindo 2020), both also shown in oribatid mites.

One of the mite families that include species which are considered to be real cosmopolites is the family Scutacaridae (Heterostigmatina, Pygmephoroidea). Scutacaridae inhabit various types of soil, where they feed on fungi, and have been reported from ecosystems of all continents except the Arctic region. Whereas scutacarid females are strongly sclerotized, males and larvae are soft-skinned, can only rarely be extracted from soil samples, and are unknown for the vast majority of species (Jagersbacher-Baumann and Ebermann 2016). The presumed cosmopolitan species have been sampled from locations all around the globe, but comprehensive studies including molecular genetic analyses supporting their species status are lacking. Almost half of all known scutacarid species are associated with other animal taxa such as ants, beetles or mammals, which commonly are used by the females for phoretic dispersal by attaching to their host using large claws on their legs I and thus help the mites to passively disperse over large distances (Baumann 2018). In nonphoretic scutacarid species, the claws on legs I are small or even absent, and their function is unclear. There are also several scutacarid species that, to my knowledge, are not phoretic, but still show a wide distribution (examples can be found in Khaustov 2008). Possible 
dispersal mechanisms for these species are the same as mentioned above. Whatever the mechanism, it is difficult to imagine a dispersal strategy for scutacarid mites that can be as effective as phoresy.

In the present work, two European scutacarid species represented by specimens mounted in microscopic slides from various European localities were selected to study the differences in morphological patterns between a phoretic and a presumed non-phoretic species. The phoretic species was Scutacarus acarorum Goeze, a species using highly mobile bumblebees (genus Bombus) for phoresy and thriving in the underground nests of its hosts. Scutacarus acarorum is a species with female dimorphism in connection with phoresy: there are phoretic females with large claws and non-phoretic females with tiny claws. When the phoretic females reach a new habitat (that is, a new bumble bee nest), they start to lay eggs and can produce both female morphs. The non-phoretic females stay in the bumble bee nest and are considered to be a kind of 'energy saving' variant responsible for rapid reproduction, producing both morphs as well (Baumann 2018). A reduced quality of food in the habitat apparently increases the proportion of phoretic females (Ebermann 1991). European populations of phoretic females of $S$. acarorum have already shown a remarkable morphological homogeneity as revealed by traditional and geometric morphometric analyses (Jagersbacher-Baumann 2015).

Populations of $S$. acarorum were now compared to populations of Scutacarus carinthiacus Ebermann, a supposed non-phoretic, soil-inhabiting species with a wide European distribution: it has been reported from Austria, Bosnia, Croatia, Germany, Great Britain, Hungary, Italy and Northern Ireland (Ebermann 1979, 1980, pers. comm.; Khaustov 2008). Scutacarus carinthiacus is supposed to be non-phoretic because the species has never been encountered in association with any animal and because it does not possess claws on leg I. Whereas populations of $S$. acarorum showed no phenotypic pattern (Jagersbacher-Baumann 2015), populations of $S$. carinthiacus are now expected to be morphologically more divergent because of reduced dispersal potential resulting in reduced gene flow and neutral evolution of morphological traits due to Brownian motion.

To compare the morphological patterns within the two species, geometric morphometric methods (GMM) based on an already successfully tested set of landmarks were used. In contrast to traditional morphometrics, where lengths, ratios or angles of different body parts are measured and 'form' (size and shape) can be analyzed, GMM use landmarks, outlines or surfaces These methods preserve the geometry of shape so that shape can easily be described using graphical representations, and the relationship between size and shape can be explained through allometric trajectories (Adams et al. 2013). GMM have proven to detect very subtle morphological variation (Karanovic et al. 2016), which makes them a valuable tool for the present research question.

\section{Material and methods}

For the experimental set-up, the optimum case would be a comparison of co-distributed populations of a phoretic and a non-phoretic species from the exact same geographic locations. This was not feasible as the occurrence of scutacarid mite species in soil is virtually unpredictable and their detection depends on more or less random encounters. Because of this, two European species available from different European locations with roughly similar geographic distances between them were selected (Fig. 1, Table 1). Individuals representing the phoretic $S$. acarorum and the supposedly non-phoretic $S$. 


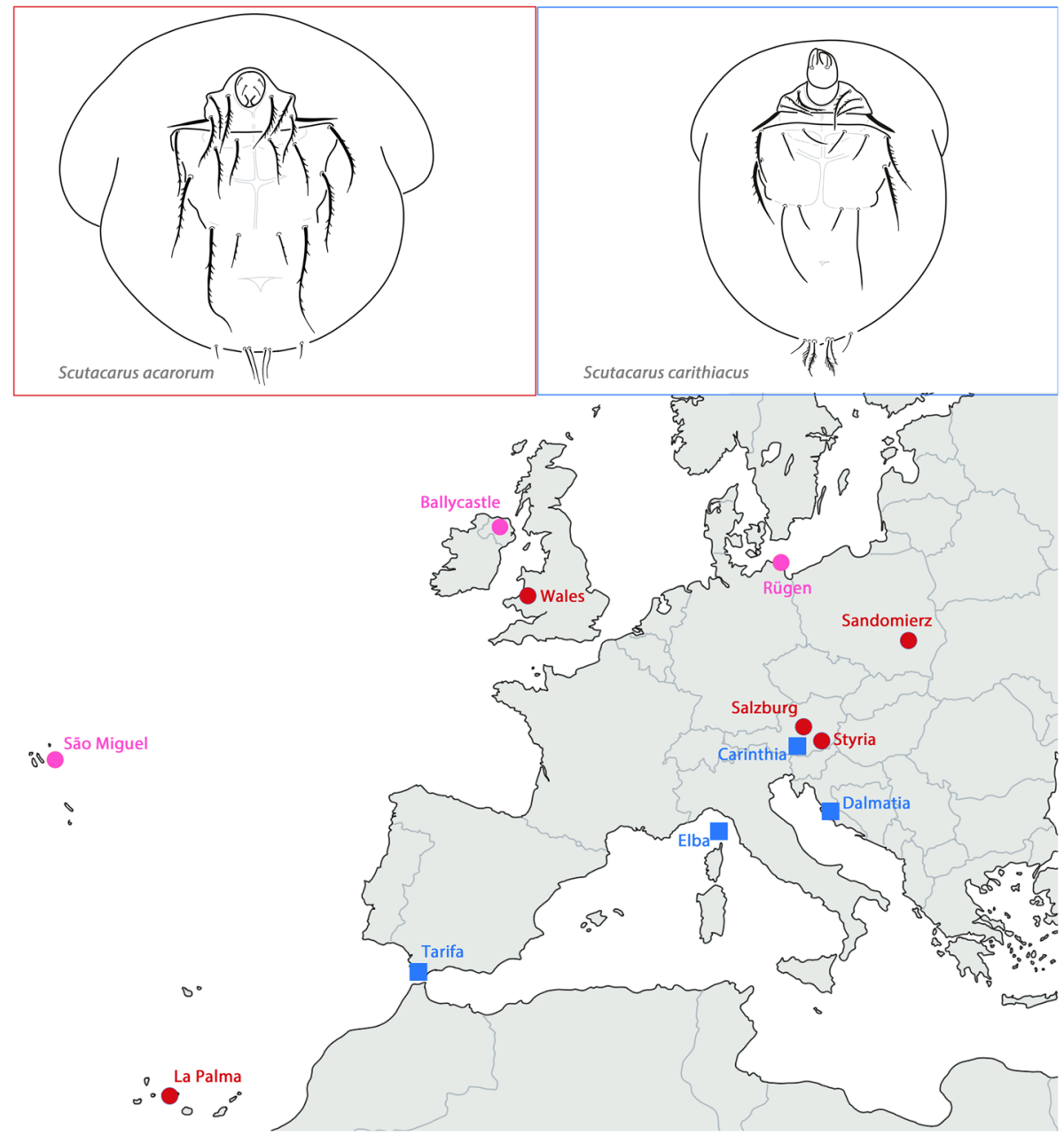

Fig. 1 Sample locations of Scutacarus acarorum and S. carinthiacus. Red dot=S. acarorum, blue square $=S$. carinthiacus, pink $d o t=S$. carinthiacus single specimens. Simplified drawings of the ventral side, legs omitted, of $S$. acarorum and $S$. carinthiacus are given. (Color figure online)

carinthiacus were available as specimens mounted in microscopic slides in the acarological collection established by E. Ebermann at the Institute of Biology, University of Graz. Additional specimens of $S$. carinthiacus were collected in 2016 by the author. From three locations (Ireland, the island of Rügen in Germany and the Azores), only single specimens of $S$. carinthiacus were available and, thus, they were included in the graphical representation of the results of the Canonical Variates Analysis, but not in further statistical analyses.

European populations of $S$. acarorum had already been studied through morphometrics (Jagersbacher-Baumann 2015) and were available from various geographic locations. For the present study, three of the populations used in the previous study as well as new specimens from the Canary Islands (La Palma) and Austria (Styria) were chosen in order to cover a geographic range and sample size similar to that of $S$. carinthiacus. 
Table 1 Collection datalocality, sample size (n), collector, year and host/habitat of the studied populations of Scutacarus acarorum and S. carinthiacus

\begin{tabular}{lrlll}
\hline Locality & $\mathrm{n}$ & Collector (of host) & Year & Host/habitat \\
\hline Scutacarus acarorum & & & & \\
Sandomierz, Poland & 10 & W. Chmielewski & 1984 & On Bombus terrestris \\
Wales, Great Britain & 10 & R. Turk & 1985 & On Bombus sp. \\
Graz, Styria, Austria & 9 & G. Kunz & 2014 & On different Bombus species \\
Thomatal, Salzburg, Austria & 9 & E. Ebermann & 1982 & Nest of B. terrestris \\
La Palma, Canary Islands, Spain & 6 & R. Zarre & 2006 & On Bombus sp. \\
Scutacarus carinthiacus & & & & \\
Carinthia, Austria & 13 & E. Ebermann & 1995 & Mixed forest litter \\
Tarifa, Spain & 12 & J. Baumann \& F. Ferragut & 2016 & Litter of Quercus \\
Elba, Italy & 9 & H. Kaiser & 1987 & No information available \\
Dalmatia, Croatia & 4 & E. Ebermann & 1996 & Litter of Maquis shrubland \\
S. Miguel, Azores, Portugal & 1 & P. Mordan & 1999 & Moist moss \\
Rügen, Germany & 1 & E. Ebermann & 2003 & Litter of Fagus \\
Ballycastle, Northern Ireland & 1 & E. Ebermann & 2001 & Soil \\
\hline
\end{tabular}

As in the previous study, only phoretic females were used because non-phoretic females were only available from Austria.

The two species are easily distinguishable because of morphological features (e.g., ventral setae, Fig. 1) and also because of a clear size difference (average body length of $S$. acarorum analyzed in this study $250 \mu \mathrm{m}$ versus $170 \mu \mathrm{m}$ for $S$. carinthiacus). In neither of the two species, discrete morphological differences between the populations could be detected.

Thirteen landmarks on the sternal plate which had already been successfully used in scutacarid mites (Jagersbacher-Baumann and Ebermann 2012; Jagersbacher-Baumann 2014, 2015) were selected for the geometric morphometric analysis. The landmarks (LMs) consist of the insertion points of the paired setae 3a (LM1 + LM12), 3b (LM 2+LM11), 3c (LM3 + LM19), 4a (LM6 + LM7), 4b (LM5 + LM8) and 4c (LM4 + LM9) and the crossing between apodeme 4 and the poststernal apodeme (LM13; Fig. 2). Digital photographs of the sternal plates of the studied specimens were taken with a Nikon Eclipse Ni-U compound microscope. A tps file of the photographs was constructed using tpsUtil and the landmarks were digitized using tpsDig2 (Rohlf 2005). The gained coordinates are available in the structure of a '.tps'-file (Supplementary file). Further analyses were performed using MorphoJ (Klingenberg 2011) and PAST 3.11 (Hammer et al. 2001). Procrustes superimposition was performed in MorphoJ and the variation within the populations (defined a priori by location) of both species was examined by Canonical Variates Analysis (CVA). For investigating the influence of size, allometric components were identified in MorphoJ and removed by multivariate regression between centroid size and Procrustes coordinates. The power of classification of populations of each species by CVA was evaluated by leaveone-out cross-validation (1000 permutations) in PAST. Mahalanobis and Procrustes distances between the populations were calculated in MorphoJ, and compared between the two species by t-test. Differences in the dispersion between the two species and between the populations within each species were evaluated in R (R Core Team 2020) by permutational analysis of multivariate dispersions with 999 permutations using the function 'permutest' in the package vegan (Oksanen et al. 2019). Linear geographic distances between 


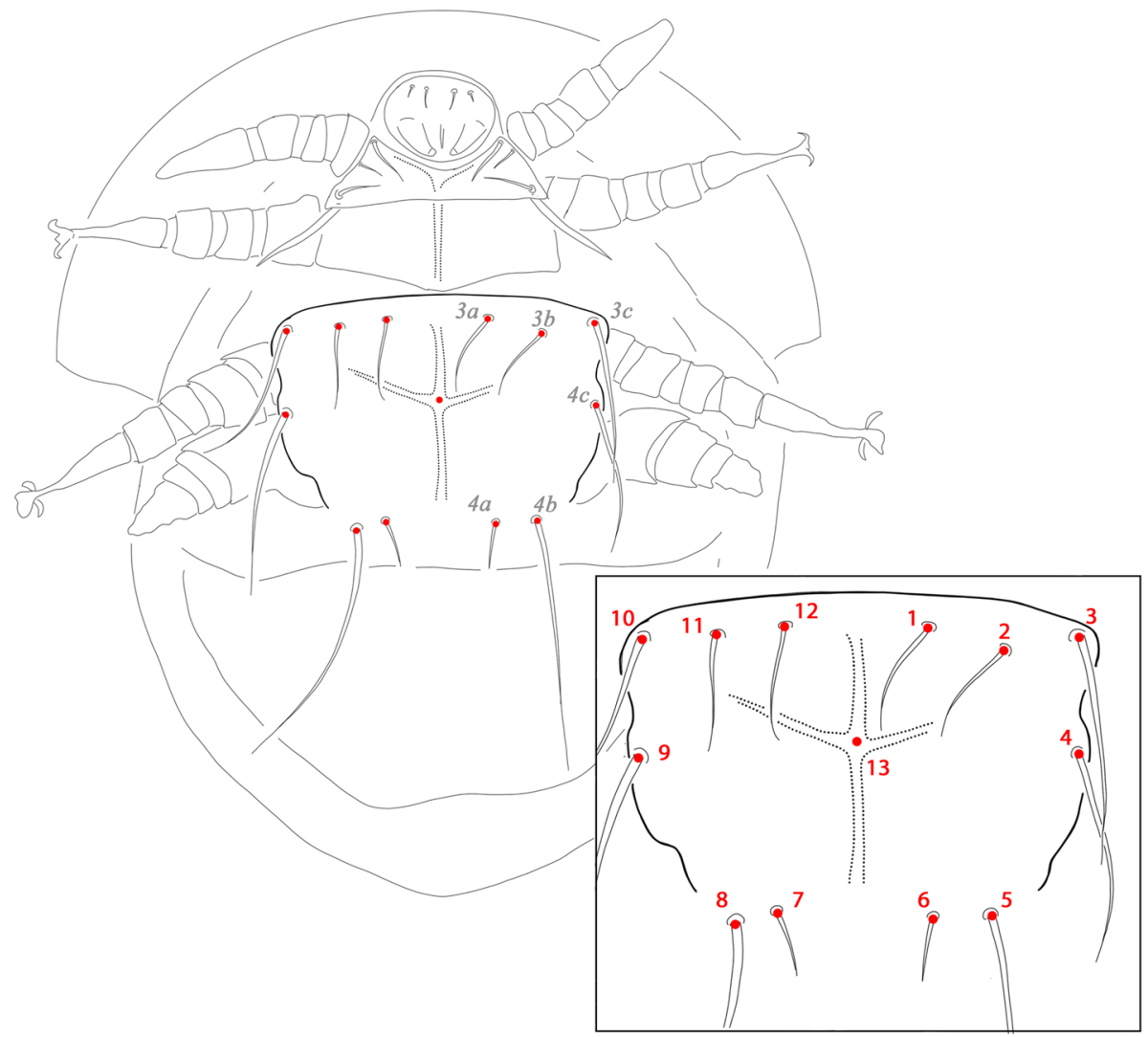

Fig. 2 Landmarks on the posterior sternal plate of a stylized scutacarid female mite used for the geometric morphometric analysis

populations were measured in GoogleMaps (www.google.at/maps) and the correlation between Mahalanobis distances and geographic distances was evaluated by Mantel test in PAST.

\section{Results}

Scutacarus acarorum and S. carinthiacus were clearly separated by CV1 in the CVA on Procrustes coordinates (Fig. 3). In comparison to S. acarorum, the posterior sternal plate of $S$. carinthiacus was narrower at level of setae $3 \mathrm{c}$ and extended at level of setae $4 \mathrm{c}$. Setae $3 \mathrm{a}$ and $3 \mathrm{~b}$ were located more closely to setae $3 \mathrm{c}$ in this species, and setae $4 \mathrm{a}$ were in a slightly more anterior position in respect to setae $4 \mathrm{~b}$.

Not surprising given the known size difference between $S$. acarorum and $S$. carinthiacus, CV1 was strongly correlated with centroid size $(\mathrm{r}=-0.83)$. In the CVA performed on both species, allometric effects explained $53.7 \%$ of the total variation and the removal of allometric components by regression and subsequent CVA on the remaining residuals resulted in a total overlap of the two species. When the two species were analyzed 


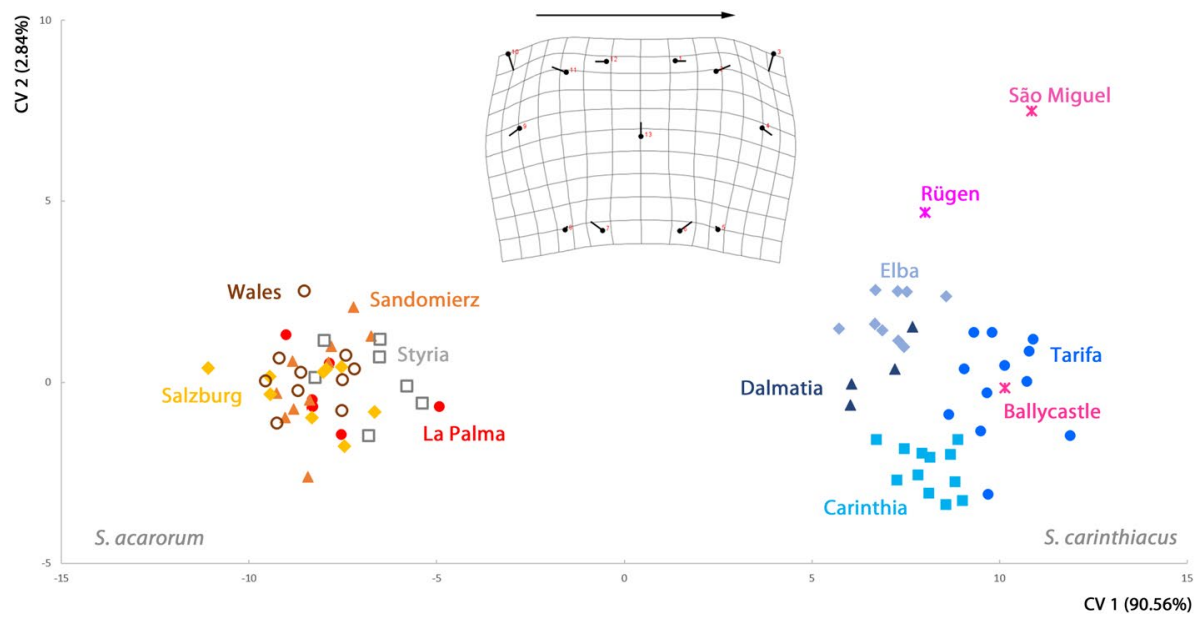

Fig. 3 Canonical variates analysis on the shape of the posterior sternal plate of populations of Scutacarus acarorum and $S$. carinthiacus, plotting the first two canonical variates. The populations (and single specimens) of both species are color-coded. Transformation grid indicates the shape differences along CV1, scale factor 15. (Color figure online)

separately regarding differences between their populations, the allometric effects were weak: they accounted for $2.7 \%$ of the variation in S. acarorum and $3.2 \%$ in S. carinthiacus.

The multivariate dispersion (average distance of the specimens to the median of the respective species) did not differ significantly between the two species neither with nor without removal of allometric components. In S. acarorum, the multivariate dispersion did not differ significantly between the populations either; in $S$. carinthiacus, the dispersion of the population from Dalmatia was significantly smaller compared to the populations from Elba and from Carinthia in the data before removal of allometric components. After removal of the allometric components, the dispersion of the population from Elba was significantly larger compared to that of the populations from Carinthia and from Tarifa.

In the joint CVA (Fig. 3), the populations of $S$. acarorum overlapped, whereas the populations of $S$. carinthiacus formed distinct clusters. A similar pattern was present when the species were analyzed separately (with as well as without removal of allometric components), although the separation between populations of both species was more pronounced in this case (Fig. 4). Accordingly, the mean of Mahalanobis distances between populations was always significantly larger in $S$. carinthiacus than in $S$. acarorum: in the joint analyses of both species as well as in the separate analyses of each species, and with and without removal of allometric components (Table 2). The mean Procrustes distances also were higher in $S$. carinthiacus than in S. acarorum, but they did not differ significantly.

Pairwise differences between populations were highly significant in both species in most cases based on Mahalanobis distances and some pairs of populations also based on Procrustes distances (Table 3). In both species, in some pairings of populations, the distance between them was larger before removal of allometric components and in other pairings the distance was larger afterwards, so no general trend was observable. Only in few cases, the significance of the results changed before and after removal of allometric components.

More meaningful than the pairwise differences, which were significant in most cases although the differences indeed were very subtle, was the power of classification by CVA: the CVA on both species with allometric components using leave-one-out cross-validation 

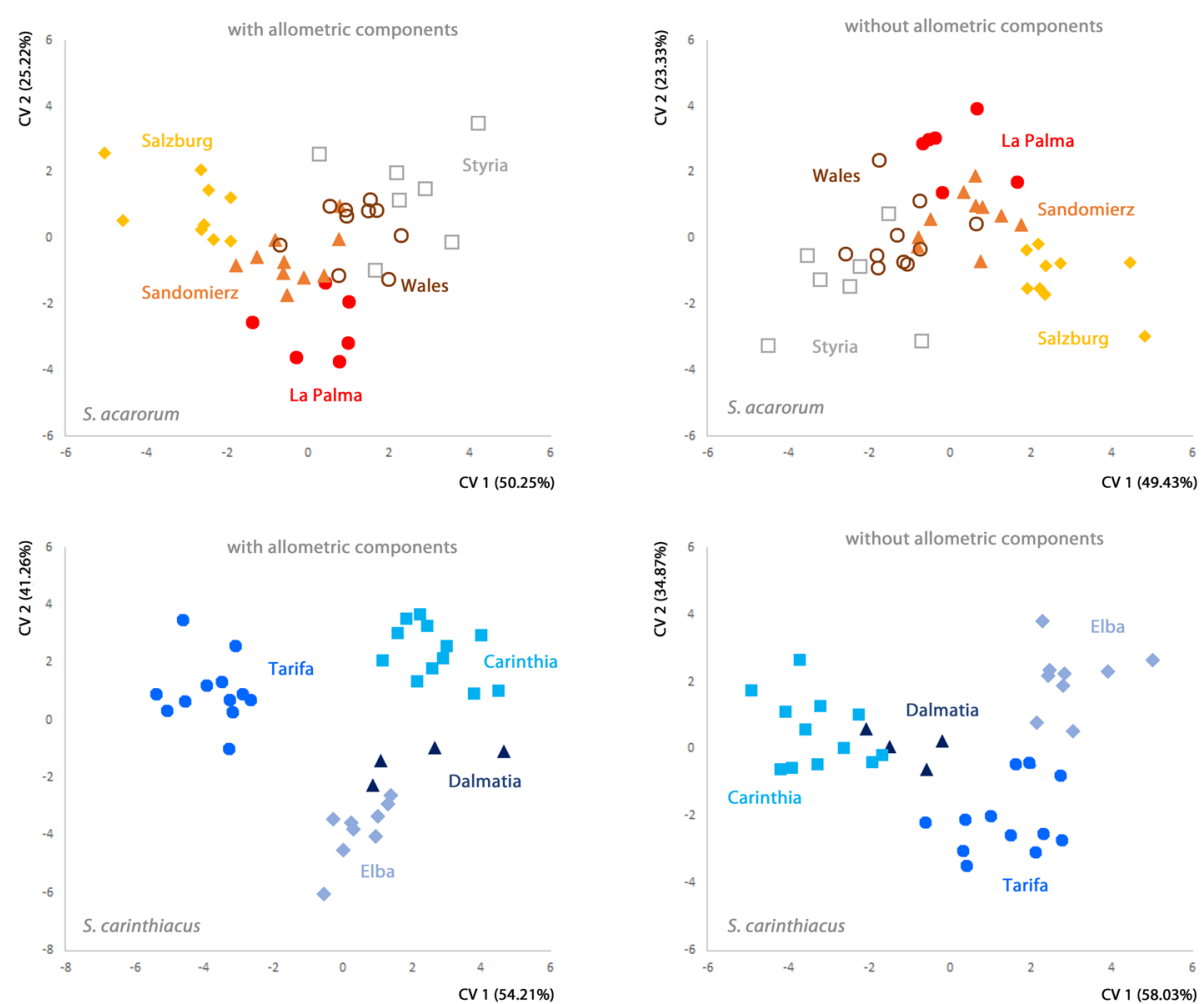

Fig. 4 Canonical variates analysis on the shape of the posterior sternal plate of populations of Scutacarus acarorum and $S$. carinthiacus analyzed separately (with and without allometric components), plotting the first two canonical variates in each plot. The populations of both species are color-coded. (Color figure online)

correctly classified $64.1 \%$ of $S$. carinthiacus specimens, but only $26.2 \%$ of $S$. acarorum. After removal of allometric components, the percentage of correctly classified specimens remained the same in S. acarorum, but dropped to $27.0 \%$ in S. carinthiacus. In the separate analyses of the two species, classification by CVA using leave-one-out cross-validation was also more successful in $S$. carinthiacus than in S. acarorum: CVA correctly classified $48.7 \%$ (40.5\% after removal of allometric components) of specimens in S. carinthiacus and only $14.3 \%$ (19.1\%, respectively) in $S$. acarorum.

No significant correlation between Mahalanobis distances and geographic distance could be detected by Mantel test in neither of the two species, neither when allometric components were present nor when they were removed.

\section{Discussion}

Scutacarus acarorum and $S$. carinthiacus cannot only be distinguished from each other because of the already known distinct differences of setae and the general size difference, but also because of a clear shape differences on the posterior sternal plate revealed by GMM. Using the same set of landmarks as in the present study, Jagersbacher-Baumann 


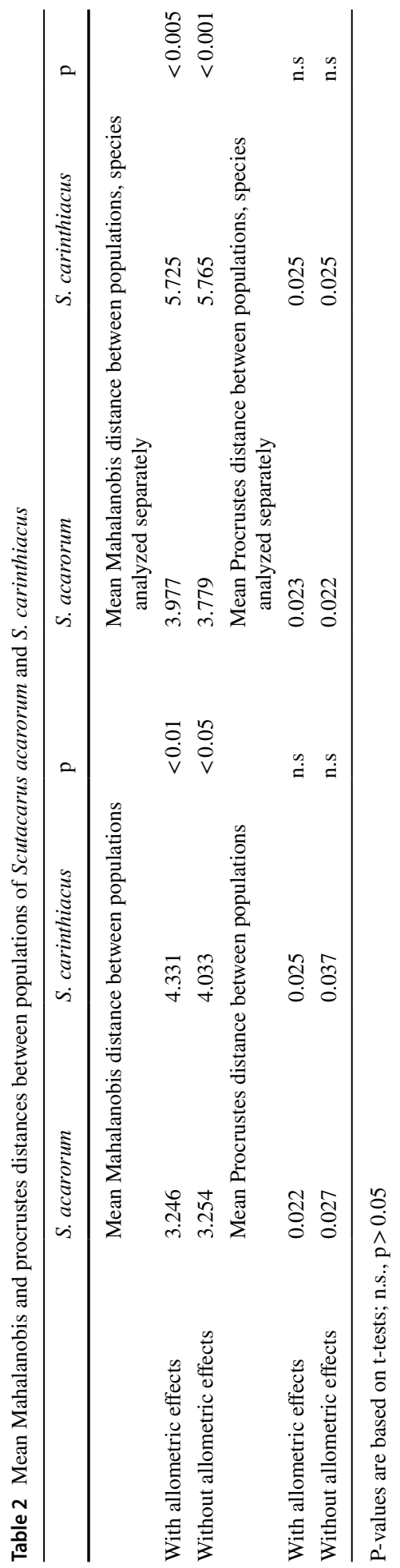


Table 3 Pairwise distances between populations of Scutacarus acarorum and S. carinthiacus as gained by CVA

\begin{tabular}{|c|c|c|c|c|c|c|c|c|c|c|}
\hline \multicolumn{11}{|c|}{$\begin{array}{l}\text { CVA on both species, no removal of allometric components } \\
\text { S. acarorum }\end{array}$} \\
\hline & La Palma & Sandomierz & Styria & Salzburg & Wales & & Carinthia & Dalmatia & Elba & Tarifa \\
\hline La Palma & & 2.92 & $3.55^{*}$ & $3.97^{*}$ & 2.41 & Carinthia & & $3.61^{*}$ & $5.08^{*}$ & $4.21^{*}$ \\
\hline Sandomierz & 0.02 & & $3.68^{*}$ & $2.95^{*}$ & 2.31 & Dalmatia & 0.02 & & 3.42 & $4.71^{*}$ \\
\hline Styria & 0.03 & $0.03^{*}$ & & $4.53^{*}$ & 2.83 & Elba & 0.02 & 0.02 & & $4.96^{*}$ \\
\hline Salzburg & 0.02 & 0.02 & $0.03^{*}$ & & $3.31^{*}$ & Tarifa & $0.03^{*}$ & $0.03^{*}$ & $0.03^{*}$ & \\
\hline Wales & 0.02 & 0.01 & 0.02 & 0.02 & & & & & & \\
\hline \multicolumn{11}{|c|}{ CVA on both species, removal of allometric components } \\
\hline S. acarorum & & & & & & & & & & \\
\hline & La Palma & Sandomierz & Styria & Salzburg & Wales & & Carinthia & Dalmatia & Elba & Tarifa \\
\hline La Palma & & $3.22^{*}$ & $3.92^{*}$ & $4.21^{*}$ & 2.74 & Carinthia & & $3.69^{*}$ & $5.00^{*}$ & $3.78^{*}$ \\
\hline Sandomierz & 0.02 & & $3.38^{*}$ & $2.94 *$ & 2.31 & Dalmatia & $0.04 *$ & & 3.9 & 3.72 \\
\hline Styria & 0.03 & 0.03 & & $4.17^{*}$ & 2.34 & Elba & 0.02 & 0.03 & & $4.10^{*}$ \\
\hline Salzburg & 0.04 & $0.03^{*}$ & 0.03 & & $3.31^{*}$ & Tarifa & $0.03^{*}$ & $0.06^{*}$ & $0.03^{*}$ & \\
\hline Wales & 0.02 & 0.01 & 0.02 & 0.03 & & & & & & \\
\hline \multirow{2}{*}{\multicolumn{11}{|c|}{$\begin{array}{l}\text { separate CVAs, no removal of allometric components } \\
\text { S. acarorum }\end{array}$}} \\
\hline & & & & & & & & & & \\
\hline & La Palma & Sandomierz & Styria & Salzburg & Wales & & Carinthia & Dalmatia & Elba & Tarifa \\
\hline La Palma & & $3.57^{*}$ & $4.63^{*}$ & $4.79^{*}$ & $3.70^{*}$ & Carinthia & & $4.45^{*}$ & $6.30^{*}$ & $6.40^{*}$ \\
\hline Sandomierz & 0.02 & & $4.09 *$ & $3.65^{*}$ & $2.71^{*}$ & Dalmatia & 0.02 & & $3.93^{*}$ & $6.81^{*}$ \\
\hline Styria & 0.03 & $0.03 *$ & & $5.40^{*}$ & 2.87 & Elba & 0.02 & 0.02 & & $6.46^{*}$ \\
\hline Salzburg & 0.02 & 0.02 & $0.03^{*}$ & & $4.36^{*}$ & Tarifa & $0.03^{*}$ & $0.03^{*}$ & $0.03^{*}$ & \\
\hline Wales & 0.02 & 0.01 & 0.02 & 0.02 & & & & & & \\
\hline \multirow{2}{*}{\multicolumn{11}{|c|}{$\begin{array}{l}\text { separate CVAs, removal of allometric components } \\
\text { S. acarorum }\end{array}$}} \\
\hline & & & & & & & & & & \\
\hline & La Palma & Sandomierz & Styria & Salzburg & Wales & & Carinthia & Dalmatia & Elba & Tarifa \\
\hline La Palma & & $3.48^{*}$ & $5.02^{*}$ & $3.83^{*}$ & $3.89^{*}$ & Carinthia & & $3.75^{*}$ & $6.45^{*}$ & $6.52^{*}$ \\
\hline Sandomierz & 0.02 & & $4.11^{*}$ & $3.19^{*}$ & $2.75^{*}$ & Dalmatia & 0.02 & & $5.62^{*}$ & $6.46^{*}$ \\
\hline Styria & 0.03 & $0.03 *$ & & $4.80^{*}$ & 2.84 & Elba & 0.02 & 0.02 & & $5.79 *$ \\
\hline Salzburg & 0.02 & 0.02 & 0.03 & & $3.88^{*}$ & Tarifa & $0.03^{*}$ & $0.03^{*}$ & $0.03^{*}$ & \\
\hline Wales & 0.02 & 0.01 & 0.02 & 0.02 & & & & & & \\
\hline
\end{tabular}

Above each diagonal: Mahalanobis distances; below each diagonal: Procrustes distances

*Indicates highly significant $(\mathrm{p}<0.01)$ differences evaluated by permutation test with 10.000 permutations

and Ebermann (2012) detected a clear separation between two population groups from Egypt and from South Africa in the scutacarid mite Heterodispus foveatus, caused mainly by differences in the positions of setae $3 \mathrm{c}, 4 \mathrm{a}$ and $4 \mathrm{~b}$. The separation revealed by GMM supported the results gained by traditional morphometrics in the respective study, and it was concluded that genetic differences caused by spatial isolation most likely explained the differences.

Analyses of the acarorum species-complex, consisting of the four presumed sister species $S$. acarorum, $S$. deserticolus, $S$. mendax and $S$. occultatus (for all except $S$. occultatus, specimens of the phoretic and non-phoretic female morph were available and analyzed separately), showed that morphometric differentiation between the species was more effective using traditional morphometrics than GMM (Jagersbacher-Baumann 2014). However, taking a closer look at the percentages of correctly classified individuals by CVA using leave-one-out cross-validation reveals that $96 \%$ of phoretic females and $84 \%$ of non-phoretic females could be correctly classified in the data gained by GMM, which are rather satisfying numbers.

These results indicate that the chosen set of landmarks has the power to differentiate between scutacarid species and can even provide sufficient resolution for detecting differences between populations. Future studies will need to test whether also a phylogenetic signal reflects different landmark configurations.

Out of the landmarks used, the ones corresponding to setae 3c and 4c (LMs 3, 4, 9, 10) are located at the very margin of the posterior sternal plate. A different position of these setae presumably indicates that the shape of the posterior sternal plate also has changed, which might influence the inner organization of the mite (e.g., space available for attachment of leg musculature) and thus have a functional implication. Almost all other landmarks indicate insertion points of setae as well (except LM13, which is located at the crossing point between two apodemata), but they are situated within the posterior sternal plate and it is not clear whether a different position of these landmarks could have a strong 
impact on the mite's biology. Like the majority of simple setae, all ventral setae are mechanoreceptors (Krantz and Walter 2009), and moderate changes in their position probably do not affect their function much. Thus, a strong selective pressure on the position of the setae does not seem very likely.

The removal of allometric components did not clearly change the encountered patterns between populations in either of the two species. Only in few pairings between populations, the distances between them or the significance of the results changed, but no general trend was observable. This supports the finding that no strong allometry is present within the species: neither in $S$. acarorum nor in $S$. carinthiacus the size of individuals considerably alters the position of the selected landmarks.

As hypothesized, populations of the presumed non-phoretic S. carinthiacus showed a clear phenotypic population structure, in contrast to the homogeneous populations of the phoretic $S$. acarorum. The phenotypic homogeneity of Central European populations of $S$. acarorum had already been demonstrated (Jagersbacher-Baumann 2015), and the addition of new populations from Austria and the Canary Islands/ La Palma in the present study did not alter this result. The bumblebee host of the population from La Palma had not been identified to species level by the collector, but as $S$. acarorum prefers large-bodied species as host and because no other bumble bee species has been reported from the Canary Islands so far (Arechavaleta et al. 2010), it is safe to assume that it was Bombus terrestris canariensis. Because of geographic isolation, this subspecies of $B$. terrestris is genetically and also morphologically well separated from European mainland populations, which in turn display homogeneity (Estoup et al. 1996; Widmer et al. 1998; Lecocq et al. 2013). In contrast to their host, Canarian $S$. acarorum mites are not morphologically distinguishable from their mainland conspecifics.

The phenotypic homogeneity within the $S$. acarorum populations from continental Europe can be explained by a bottleneck event in the last ice age, a rather recent redistribution at the beginning of the last warm period and a well-maintained gene flow because of the high mobility of the bumblebee hosts (Estoup et al. 1996; Widmer et al. 1998; Jagersbacher-Baumann 2015). A similar result was obtained for Imparipes burgeri, a scutacarid mite that is phoretic on a variety of Central European Hymenoptera (most of all on Halictidae). In a traditional morphometric study of populations from Austria, Germany and Belgium associated with a total of 45 host species, Ebermann et al. (2013) also revealed morphological homogeneity of the I. burgeri populations. It is more complicated to find an explanation for the lack of morphological differences between the mites from La Palma and from continental Europe. The earlier study on $S$. acarorum also included a population from New York (USA), and not even this population showed clear morphometric differences from the European populations (Jagersbacher-Baumann 2015). These results indicate that $S$. acarorum has a very conserved phenotype not only because of well-maintained gene flow, but also because of morphological stasis. Such a morphological stasis has also been reported, for example, for littoral oribatid mites, where it is supposed to be the result of stabilizing selection due to the extreme habitat of the littoral zone (Pfingstl et al. 2019). Morphological stasis in general is considered to be the result of low-standing genetic variation, developmental constraints on the morphospace, and/or a relatively constant ecology of a taxon (Struck et al. 2018). The microclimate inside belowground bumblebee nests is favorable for mites because of an abundance of stored food reserves and debris (Baumann 2018); moreover, it is considered to be little variable even across geographical localities (Haas et al. 2019), and these stable conditions could explain the morphological stasis of $S$. acarorum. Another important stabilizing factor leading to the conserved phenotype might be the phoretic lifestyle. The results of other studies on Scutacaridae (Ebermann 
1991; Jagersbacher-Baumann 2014) also support the idea that phoresy may constrain the morphospace: the respective studies indicate that in dimorphic scutacarid species (such as S. acarorum), the intraspecific morphometric variability of non-phoretic females is higher than that of phoretic females. The more conserved phenotype of the phoretic females might be necessary for the successful performance of phoresy. Unfortunately, non-phoretic females of $S$. acarorum were not available from different geographic locations to test whether their morphological pattern mirrors that of their phoretic conspecifics. Similar host-associated adaptive pressures have also been reported for other ectosymbionts such as feather mites (Stefan et al. 2018).

In contrast to $S$. acarorum, the populations of $S$. carinthiacus showed clearer phenotypic differences, which suggests that there is no or only very limited gene flow between them. At present, it is not possible to determine whether the subtle morphometric disparity is due to neutral evolution or due to adaptation to ecologically different (micro)habitats between geographic locations. In any case, there seem to be no constraints leading to morphological stasis like in $S$. acarorum.

No phenogeographical pattern linking the phenotypic differences with geography was observable: for example, the Mahalanobis distances between the populations from Carinthia and Elba were higher than the Mahalanobis distances between the populations from Carinthia and Tarifa, although the linear geographic distance between the latter is considerably higher (520 vs. $2005 \mathrm{~km}$ ). Geographic vicinity alone apparently is not sufficient to reconstruct the phenotypic (and probably also phylogenetic) relationships or colonization routes of S. carinthiacus. Our knowledge about the dispersal mechanisms of small flightless arthropods that are non-phoretic is still very limited, and they have never been studied in non-phoretic Scutacaridae. As mentioned before, S. carinthiacus is considered to be non-phoretic because it is a species lacking claws on legs I (Baumann 2018). However, a recent discovery demonstrated that there are also scutacarid species that perform phoresy although they do not possess claws on leg I and instead use large pulvilli for attachment on their termite host (Baumann et al. 2018); this finding renders the previous strict division of phoretic and non-phoretic scutacarid species uncertain. The results of the present study still support the assumption of a reduced capability to cross geographic barriers in S. carinthiacus; occasional dispersal through phoresy might have happened in the past, explaining the wide geographic range of the species. Phoresy still might take place occasionally at the present, but since $S$. carinthiacus never has been encountered in association with potential hosts, it seems not very likely.

At least some of the geographically and morphometrically separated populations of $S$. carinthiacus studied here could represent 'cryptic' species. The concept of cryptic species refers to species that are morphologically indistinguishable, but show sufficient genetic differences so that it seems justified to establish them as separate species, and such species are being discovered in virtually all animal taxa (e.g., Fišer et al. 2018; Korshunova et al. 2019). Cryptic speciation is a strongly discussed topic nowadays and is controversial because of different species concepts, but also because of different approaches on how to define morphological disparity. More thorough studies conducted after molecular genetic analyses (for example, on fine-scale morphology, behavior, chemical properties) usually support the new species status (Skoracka et al. 2015), which indicates that 'cryptic' species often only are an example of inadequate taxonomy. In mites, several studies demonstrated that genetically well separated species did not show differences in distinct morphological characters and only differed slightly in morphometric analyses (e.g., Knee et al. 2012; Pfingstl et al. 2019; Schäffer et al. 2019). The morphometric differences revealed in $S$. carinthiacus thus point to the possible existence of a species complex, even more so as 
phenotypic variation analyzed by GMM can be as sensitive as molecular data (Karanovic et al. 2016). However, since the present study had another objective and was only based on landmarks on the posterior sternal shield, the identification of new species is not justified yet.

\section{Conclusion}

The present study showed that geographically separated populations of two scutacarid species with presumed different dispersal abilities display different phenotypic patterns. Whereas distinct diagnostic morphological characters did not differ between the populations of either species, clear morphometric differences were detected in one of the species via GMM. The differences in the phenotypic patterns of $S$. acarorum and $S$. carinthiacus can probably be explained by different levels of gene flow between the populations of the two species caused by differing dispersal abilities.

Mite material in long-established acarological collections often is only available in the form of microscopic slides or had been stored inadequately (e.g., in low-concentration ethanol at room temperature) so that molecular genetic analyses are not feasible. GMM exceed the possibilities of traditional morphological analyses and can thus be recommended as a powerful and sensitive tool for the study of such material (e.g., analysis of morphological variation, detection of cryptic diversity, or reconstruction of morphology-based phylogenies).

Acknowledgements The author acknowledges the financial support by the University of Graz. She also thanks Dr. Ernst Ebermann for making his collection of microscopic slides available and Dr. Michaela Kerschbaumer (both University of Graz) for her help with MorphoJ.

Funding Open Access funding provided by University of Graz.

Open Access This article is licensed under a Creative Commons Attribution 4.0 International License, which permits use, sharing, adaptation, distribution and reproduction in any medium or format, as long as you give appropriate credit to the original author(s) and the source, provide a link to the Creative Commons licence, and indicate if changes were made. The images or other third party material in this article are included in the article's Creative Commons licence, unless indicated otherwise in a credit line to the material. If material is not included in the article's Creative Commons licence and your intended use is not permitted by statutory regulation or exceeds the permitted use, you will need to obtain permission directly from the copyright holder. To view a copy of this licence, visit http://creativecommons.org/licenses/by/4.0/.

\section{References}

Adams DC, Rohlf FJ, Slice DE (2013) A field comes of age: geometric morphometrics in the 21st century. Hystrix, It J Mamm 24(1):7-14. https://doi.org/10.4404/hystrix-24.1-6283

Arechavaleta M, Rodríguez S, Zurita N, Gracía A (coord.) (2010) Lista de especies silvestres de Canarias. Hongos, plantas y animales terrestres. 2009. Gobierno de Canarias.

Auger P, Tixier M-S, Kreiter S, Fauvel G (1999) Factors affecting ambulatory dispersal in the predaceous mite Neoseiulus californicus (Acari: Phytoseiidae). Exp Appl Acarol 23:235-250. https://doi. org/10.1023/A:1006019014708

Baumann J (2018) Tiny mites on a great journey- a review on scutacarid mites as phoronts and inquilines (Heterostigmatina, Pygmephoroidea, Scutacaridae). Acarologia 58(1):192-251. https://doi. org/10.24349/acarologia/20184238

Baumann J, Ferragut F, Šimić S. (2018) Lazy hitchhikers? Preliminary evidence for within-habitat phoresy in pygmephoroid mites (Acari, Scutacaridae). Soil Org 90 (3): 95-99; DOI https://doi.org/10.25674 /28y9-2v49 
Binns ES (1982) Phoresy as migration- some functional aspects of phoresy in mites. Biol Rev 57:571-620. https://doi.org/10.1111/j.1469-185X.1982.tb00374.x

Boykin LS, Campbell WV (1984) Wind Dispersal of the Twospotted Spider Mite (Acari: Tetranychidae) in North Carolina Peanut Fields. Environ Entomol 13(1):221-227. https://doi.org/10.1093/ee/13.1.221

Duffy JE (1993) Genetic population structure in two tropical sponge-dwelling shrimps that differ in dispersal potential. Mar Biol 116:459-470. https://doi.org/10.1007/BF00350063

Ebermann E (1979) Ein Beitrag zur Erforschung der Milben-Familie Scutacaridae (Acari- Trombidiformes) in Österreich und angrenzenden Gebieten. Carinthia II 169:259-280

Ebermann E (1980) Neue Funde bodenbewohnender Milben (Fam. Scutacaridae) aus Kärnten und benachbarten Gebieten. Carinthia II 170:347-363

Ebermann E (1991) Das Phänomen Polymorphismus in der Milbenfamilie Scutacaridae (Acari, Heterostigmata, Tarsonemina, Scutacaridae). Zoologica 141:76 pp. Stuttgart

Ebermann E, Hall M, Hausl-Hofstätter U, Jagersbacher-Baumann JM, Kirschner R, Pfingstl T, Plassnig E (2013) A new phoretic mite species with remarks to the phenomenon 'Sporothecae' (Acari, Scutacaridae; Hymenoptera, Aculeata). Zool Anz 252(2):234-242. https://doi.org/10.1016/j. jcz.2012.06.003

Estoup A, Solignac M, Cornuet JM, Goudet J, Scholl A (1996) Genetic differentiation of continental and island populations of Bombus terrestris (Hymenoptera: Apidae) in Europe. Mol Ecol 5:19-31. https ://doi.org/10.1111/j.1365-294X.1996.tb00288.x

Fišer C, Robinson CT, Malard F (2018) Cryptic species as a window into the paradigm shift of the species concept. Mol Ecol 27:613-635. https://doi.org/10.1111/mec.14486

Haas SM, Cardinal S, Beaulieu F, Forrest JRK (2019) Mite-y bees: bumblebees (Bombus spp., Hymenoptera: Apidae) host a relatively homogeneous mite (Acari) community, shaped by bee species identity but not by geographic proximity. Ecol Entomol 44:333-346. https://doi.org/10.1111/een.12706

Hammer $\emptyset$, Harper DAT, Ryan PD (2001) PAST: paleontological statistics software package for education and data analysis. Paleontol Electron 4:9

Haye PA, Segovia NI, Muñoz-Herrera NC, Gálvez FE, Martínez A, Meynard A, Pardo-Gandarillas MC, Poulin E, Faugeron S (2014) Phylogeographic Structure in Benthic Marine Invertebrates of the Southeast Pacific Coast of Chile with Differing Dispersal Potential. PLoS ONE 9(2):e88613. https ://doi.org/10.1371/journal.pone.0088613

Jagersbacher-Baumann J (2014) Species differentiation of scutacarid mites (Heterostigmatina) using multivariate morphometric methods. Exp Appl Acarol 62:279-292. https://doi.org/10.1007/s1049 3-013-9747-x

Jagersbacher-Baumann J (2015) Traditional and geometric morphometric analyses reveal homogeneity in European Scutacarus acarorum Goeze, 1780 populations (Acari: Scutacaridae: Heterostigmatina). J Nat Hist 49(19-20):1173-1190

Jagersbacher-Baumann J, Ebermann E (2012) Fungal spore transfer and intraspecific variability of a newly described African soil mite (Heterostigmata, Scutacaridae, Heterodispus). Zool Anz 251:101-114. https://doi.org/10.1016/j.jcz.2011.05.008

Jagersbacher-Baumann J, Ebermann E (2016) Support for the underrepresented sex: new descriptions of scutacarid males (Acari, Heterostigmatina). Zootaxa 4179 (3): 371-409. http://doi.org/https://doi. org/10.11646/zootaxa.4179.3.3

Jung C, Croft BA (2001) Aerial dispersal of phytoseiid mites (Acari: Phytoseiidae): estimating falling speed and dispersal distance of adult females. Oikos 94:182-190. https://doi.org/10.103 4/j.1600-0706.2001.11044.x

Karanovic T, Djurakic M, Eberhard SM (2016) Cryptic Species or Inadequate Taxonomy? Implementation of 2D Geometric Morphometrics Based on Integumental Organs as Landmarks for Delimitation and description of Copepod Taxa. Syst Biol 65:304-327. https://doi.org/10.1093/sysbio/syv088

Khaustov AA (2008) Mites of the family Scutacaridae of Eastern Palaearctic. Akademperiodyka.

Klingenberg CP (2011) MorphoJ: an integrated software package for geometric morphometrics. Mol Ecol Resour 11(2):353-357. https://doi.org/10.1111/j.1755-0998.2010.02924.x

Knee W, Beaulieu F, Skevington JH, Kelso S, Forbes MR (2012) Cryptic species of mites (Uropodoidea: Uroobovella spp.) associated with burying beetles (Silphidae: Nicrophorus): The collapse of a host generalist revealed by molecular and morphological analyses. Mol Phylogenet Evol 65(1): 276286. https://doi.org/https://doi.org/10.1016/j.ympev.2012.06.013

Korshunova T, Picton B, Furfaro G, Mariottini P, Pontes M, Prkić J, Fletcher K, Malmberg K, Lundin K, Martynov A (2019) Multilevel fine-scale diversity challenges the 'cryptic species' concept. Sci Rep 9:6732. https://doi.org/10.1038/s41598-019-42297-5

Krantz GW, Walter DE (2009) A manual of Acarology. Texas Tech University Press, Lubbock 
Lebedeva NV, Krivolutsky DA (2003) Birds Spread Soil Microarthropods to Arctic Islands. Dokl Biol Sci 391:329-332

Lecocq T, Vereecken NJ, Michez D, Dellicour S, Lhomme P, Valterová I, Rasplus J, Rasmont P (2013) Patterns of genetic and reproductive traits differentiation in mainland vs. Corsican populations of bumblebees PLoS ONE 8:e65642

Lehmitz R, Russell D, Hohberg K, Christian A, Xylander WER (2011) Wind dispersal of oribatid mites as a mode of migration. Pedobiologia 54(3):201-207. https://doi.org/10.1016/j.pedobi.2011.01.002

Lehmitz R, Russell D, Hohberg K, Christian A, Xylander WER (2012) Active dispersal of oribatid mites into young soils. Appl Soil Ecol 55:10-19. https://doi.org/10.1016/j.apsoil.2011.12.003

Lindo Z (2020) Transoceanic dispersal of terrestrial species by debris rafting. Ecography 00:1-9. https://doi. org/10.1111/ecog. 05155

Lomolino MV, Riddle BRC, Whittaker RJ, Brown JH (2010) Biogeography. Sunderland, MA.560pp.

Michalska K, Skoracka A, Navia D, Amrine JW (2010) Behavioural studies on eriophyoid mites: an overview. Exp Appl Acarol 51:31-59. https://doi.org/10.1007/s10493-009-9319-2

Miller-Butterworth CM, Jacobs DS, Harley EH (2003) Strong population substructure is correlated with morphology and ecology in a migratory bat. Nature 424 (6945): 187-191. https://doi:https://doi. org/10.1038/nature01742

Oksanen J, Blanchet FG, Kindt R, Legendre P, Minchin PR, O'Hara B, Simpson GL, Solymos P, Wagner H (2019) vegan: Community Ecology Package. R package version 2.5-6. https://CRAN.R-project.org/ package $=$ vegan. Accessed 13 February 2020

Papadopoulou A, Anastasiou I, Keskin B, Vogler AP (2009) Comparative phylogeography of tenebrionid beetles in the Aegean archipelago: the effect of dispersal ability and habitat preference. Mol Ecol 18:2503-2517. https://doi.org/10.1111/j.1365-294X.2009.04207.x

Pfingstl T (2013) Resistance to fresh and salt water in intertidal mites (Acari: Oribatida): implications for ecology and hydrochorous dispersal. Exp Appl Acarol 61:87-96. https://doi.org/10.1007/s1049 3-013-9681-y

Pfingstl T (2017) The marine-associated lifestyle of ameronothroid mites (Acari, Oribatida) and its evolutionary origin: a review. Acarologia 57(3):693-721. https://doi.org/10.24349/acarologia/20174197

Pfingstl T, Baumann J, Lienhard A (2019) The Caribbean enigma: the presence of widely distributed cryptic groups of intertidal mites (Arachnida, Acari, Oribatida). Org Divers Evol 19:609-623. https://doi. org/10.1007/s13127-019-00416-0

R Core Team (2020) R: A language and environment for statistical computing. R Foundation for Statistical Computing, Vienna, Austria. https://www.R-project.org/. Accessed 12 October 2019.

Rohlf FJ (2005) TPS Software Series. State University of New York, Stony Brook, Department of Ecology and Evolution

Schäffer S, Kerschbaumer M, Koblmüller S (2019) Multiple new species: Cryptic diversity in the widespread mite species Cymbaeremaeus cymba (Oribatida, Cymbaeremaeidae). Mol Phylogenet Evol 135:185-192. https://doi.org/10.1016/j.ympev.2019.03.008

Schuppenhauer MM, Lehmitz R, Xylander WER (2019) Slow-moving soil organisms on a water highway: aquatic dispersal and survival potential of Oribatida and Collembola in running water. Mov Ecol 7:20. https://doi.org/10.1186/s40462-019-0165-5

Skoracka A, Magalhães S, Rector BG, Kuczyński L (2015) Cryptic speciation in the Acari: a function of species lifestyles or our ability to separate species? Exp Appl Acarol 67:165-182. https://doi. org/10.1007/s10493-015-9954-8

Stefan LM, Gómez-Díaz E, Mironov SV, Gonzaléz-Solís J, McCoy KD (2018) 'More Than Meets the Eye’: Cryptic Diversity and Contrasting Patterns of Host-Specificity in Feather Mites Inhabiting Seabirds. Front Ecol Evol 6:97. https://doi.org/10.3389/fevo.2018.00097

Struck TH, Feder JL, Bendiksby M, Birkeland S, Cerca J, Gusarov VI, Kistenich S, Larsson K-H, Hsiong Liow L, Nowak MD, Stedje B, Bachmann L, Dimitrov D (2018) Finding evolutionary processes hidden in cryptic species. Trends Ecol Evol 33:153-163. https://doi.org/10.1016/j.tree.2017.11.007

Widmer A, Schmid-Hempel P, Estoup A, Scholls A (1998) Population genetic structure and colonization history of Bombus terrestris s.l. (Hymenoptera: Apidae) from the Canary Islands and Madeira. Heredity 81:563-572. https://doi.org/10.1046/j.1365-2540.1998.00407.x

Publisher's Note Springer Nature remains neutral with regard to jurisdictional claims in published maps and institutional affiliations. 